\title{
MARCAS DE IDENTIDAD, ATRIBUTOS SOCIALES DESEABLES Y FENOTIPOS COMPARTIDOS. UN ANÁLISIS A PARTIR DE LA DONACIÓN DE GAMETOS EN URUGUAY
}

\section{Identity Marks, Desirable Social Attributes and Shared Phenotypes. An Analysis Based on Gamete Donation in Uruguay}

\author{
Mariana Viera Cherro* \\ * Universidad de la República (Uruguay) \\ marianaviera@yahoo.com
}

\section{Palabras clave}

Reproducción asistida

Gametos

Raza

Etnia

Filiación

Identidad

\section{Keywords}

Assisted reproduction Gametes Race Ethnicity Filiation Identity

\begin{abstract}
Resumen
La gestión de gametos -óvulos y esperma- de donación para tratamientos de reproducción humana asistida involucra la captación de personas dispuestas a dar parte de su biología o fertilidad, una selección para definir quiénes ingresan efectivamente en el proceso de donación, el desarrollo de un "trabajo clínico" orientado a la producción de ese material reproductivo y, finalmente, la distribución los gametos entre personas o parejas receptoras. El proceso de selección que define quiénes ingresan efectivamente como donantes implica una valoración de la persona y de los gametos que puede aportar. Se ponen en juego en esta valoración atributos concebidos de modos diversos - capacidad reproductiva, características fenotípicas, características étnico-raciales, atributos genéticos, intelectuales, entre otros-, que hablan de la lectura que la sociedad hace del material biológico y de lo que se considera valorable para la reproducción de la sociedad en su conjunto y para el establecimiento de una relación filial específica. En este artículo analizo cómo se definen estos atributos y cuáles se privilegian al momento de gestionar la reproducción social y la producción de una relación social filial específica. No se trata de analizar la gestión de material reproductivo de donación para tecnologías de reproducción humana asistida en sí misma, sino como vía para entender cómo la sociedad uruguaya concibe las relaciones entre biología, identidad, filiación y reproducción.
\end{abstract}

\section{Abstract}

The management of gametes - ovules and sperm - of donation for assisted human reproduction treatments involves the recruitment of people willing to give part of their biology or fertility, a selection to define those who actually enter the donation process, the development of a "clinical work" oriented to the production of that reproductive material and finally, the distribution of the gametes between people or receiving couples. The selection process that defines those who actually become donors, implies an assessment of the person and the gametes that can contribute. At stake in this assessment are attributes conceived in different ways - reproductive capacity, phenotypic characteristics, ethnic / racial characteristics, genetic, intellectual attributes, among others - that speak of the conception that society makes of biological material and of what is considered valuable for the reproduction of the society as a whole and for the establishment of a specific filial relationship. In this article, I analyze how these attributes are defined and which are privileged when managing social reproduction and the production of a specific filial social relationship. It is not about analyzing the management of reproductive donation material for assisted human reproduction technologies itself, but as a way to understand how Uruguayan society conceives the relationships between biology, identity, filiation and reproduction.

Viera Cherro, M. (2018). Marcas de identidad, atributos sociales deseables y fenotipos compartidos. Un análisis a partir de la donación de gametos en Uruguay. Papeles del CEIC. International Journal on Collective Identity Research, vol. 2018/2, papel 195, CEIC (Centro de Estudios sobre la Identidad Colectiva), UPV/EHU Press, http://dx.doi.org/10.1387/pceic. 18880 


\section{INTRODUCCIÓN ${ }^{1}$}

En este artículo doy cuenta de algunas de las conexiones que la sociedad uruguaya realiza entre biología, identidad, filiación y reproducción a partir del análisis de la gestión de gametos para intervenciones médico reproductivas en el campo de las tecnologías de reproducción humana asistida (TRHA).

Analizo cómo esta gestión atribuye valoraciones al material reproductivo de donación y cómo estas se tramitan en la inclusión de material reproductivo de donación en intervenciones biotecnológicas con objetivos de reproducción y filiación. Recordemos que las TRHA no solo buscan la reproducción biológica, sino una reproducción biológica que atienda a los requerimientos sociales para el establecimiento de vínculos filiatorios (Franklin, 1997).

En el primer apartado enmarco, de forma somera, el contexto legal y empírico en el cual se gestiona la donación de gametos para TRHA en Uruguay. Repaso los orígenes de la reproducción humana asistida en el país para luego focalizarme en los aspectos vertebrales de la actual legislación y de la práctica en lo que concierne a la gestión de gametos de donación. A continuación, describo la estrategia metodológica empleada para construir los datos a partir de los cuales trabajo.

Los apartados siguientes están dedicados al análisis de los datos. En el primero, señalo cuáles son los atributos sociales que desde la gestión de la donación de gametos se conciben como deseables y cómo se trabaja desde esta gestión para asegurarse de contar con tales atributos. Luego abordo la gestión de esos atributos a nivel de la relación filial, para culminar con el análisis de la gestión de estos atributos a nivel de la sociedad en su conjunto.

$1 \mathrm{El}$ análisis que presento en este artículo parte de los datos empíricos construidos en mi trabajo de campo para la tesis del Doctorado en Antropología, que curso en la Facultad de Humanidades y Ciencias de la Educación de la Universidad de la República (Uruguay). Esta investigación aún está en curso, por lo cual las reflexiones que expongo tienen un carácter preliminar. Agradezco a la Agencia Nacional de Investigación e Innovación (ANII) haberme otorgado una beca de doctorado para poder realizar mi investigación (marzo de 2015 a setiembre de 2017) y a la Comisión Académica de Posgrados (CAP) de la Universidad de la República por otorgarme la Beca de Finalización de Doctorado (marzo de 2018 a marzo de 2019). 


\section{CONDICIONES LEGALES Y EMPÍRICAS PARA EL ACCESO A GAMETOS DE DONACIÓN EN URUGUAY}

El acceso a gametos de donación -óvulos y esperma- se plantea como una necesidad para la realización de intervenciones biotecnológicas con objetivos reproductivos en los casos en que la persona o la pareja que las solicita no pueda producir uno o ambos gametos. El semen puede utilizarse en intervenciones de baja complejidad, que suponen la introducción del esperma en la vagina durante la ovulación, mientras que ambos gametos pueden ser manipulados e incorporados en intervenciones de alta complejidad o in vitro.

También puede recurrirse a gametos de donación con fines de investigación. Sin embargo, nos concentramos en su uso en el campo de la reproducción porque es en ese ámbito en el que se pueden visualizar las conexiones que nos proponemos analizar.

En Uruguay las tecnologías de reproducción humana asistida se introdujeron a partir del trabajo del ginecólogo Gerardo Bossano, quien fundó el Centro de Esterilidad Montevideo (CEM) (Viera Cherro, 2015). EI CEM inició su labor en 1987 y logró el primer nacimiento por fertilización in vitro en Uruguay el 20 de marzo de 1990. La mayoría de quienes se especializan en estas biotecnologías se ha formado en centros en Europa, principalmente en el Instituto Valenciano de Infertilidad (IVI) y también en Estados Unidos y en Argentina.

Luego de más de dos décadas de trabajar sin un marco legal, en noviembre de 2013 se aprobó en Uruguay la Ley $19.167^{2}$ que regula la actividad en el campo de la reproducción humana asistida. La ley permite también el acceso a los "tratamientos"3 mediante un copago por parte del Estado: "El Estado garantizará que las técnicas de reproducción humana asistida queden incluidas dentro de las

2 Texto completo consultable en: https://www.impo.com.uy/bases/leyes/19167-2013. Última consulta: 10/05/2018.

3 Entrecomillo la palabra tratamientos por entender que en algunos casos existe una patología a curar que impide el embarazo, pero no siempre es así. En muchas oportunidades el embarazo se produce sin curar la patología o incluso sin identificar qué es lo que impide la concepción. En otros casos se trata incluso de parejas que simplemente quieren descendencia biológicamente vinculada (Diniz y Gómez Costa, 2006) pero sin tener relaciones heterosexuales coitales (Viera Cherro, 2015). Estamos así de acuerdo con Diniz y Gómez Costa (2006) cuando afirman que las TRHA son tecnologías fundamentalmente abocadas a la producción de una descendencia biológica, más que a la cura de una enfermedad, aunque se suela presentarlas de este último modo. 
prestaciones del Sistema Integrado de Salud con el alcance dispuesto por la presente ley" (art. 3, Disposiciones Generales), y contemplará la atención de parejas "biológicamente impedidas" de concebir ${ }^{4}$, así como de mujeres con independencia de su estado civil (art. 2, Ley 19.167).

El Sistema Nacional Integrado de Salud (SNIS) fue creado por la Ley $18.211^{5}$ con el objetivo de asegurar el acceso a los servicios de salud para todos quienes residan en el país, articulando prestadores públicos y privados. Dentro del SNIS participan como prestadores de tratamientos de reproducción humana asistida los centros hospitalarios públicos y las mutualistas, que solo realizan procedimientos de baja complejidad, y tres clínicas privadas, que brindan intervenciones tanto de baja como de alta complejidad.

En el artículo 12 del capítulo III de la ley, concerniente a la donación de gametos y embriones, se señala que la donación de gametos debe ser anónima y altruista, aunque quienes reciben gametos o embriones de donación tienen derecho a tener información general sobre las características fenotípicas del donante (art. 15, cap. III).

La donación requiere la firma de un consentimiento informado y la ley prevé la revocación de la donación si quien dona necesita posteriormente para sí los gametos donados. La donación no genera vínculo filiatorio entre quien dona y la persona nacida con el material biológico de donación. Quienes donan deben ser mayores de edad y deben acreditar un buen estado de salud psicofísica, demostrando que “(...) no padecen enfermedades genéticas, hereditarias o infecciosas que comprometan la viabilidad del embrión o que sean trasmisibles a la descendencia y no puedan ser tratadas luego del nacimiento" (art. 13, cap. III).

El acceso a gametos de donación para TRHA se produce a través de los denominados Bancos de Gametos o Programas de Donación de Gametos. En el artículo 16 de la Ley 19.167 se señala que "Las instituciones públicas y privadas autorizadas por el Ministerio de Salud

4 La ley no aclara si se trata de parejas heterosexuales $u$ homosexuales, por lo cual quedan en principio incluidas ambas, a pesar de que se excluyen luego las parejas homosexuales masculinas, en tanto no se les permite la subrogación de útero. Para que la subrogación se habilite, con determinadas condiciones, debe existir la demanda de una mujer "(...) cuyo útero no pueda gestar su embarazo (...)" (art. 25, cap. IV).

5 Texto completo consultable en: https://www.impo.com.uy/bases/leyes/18211-2007/61. Última consulta: 08/04/2018. 
Pública para realizar técnicas de reproducción humana asistida podrán tener sus bancos de gametos, para lo cual deberán ser previamente autorizadas por dicho Ministerio y quedar sujetas a su supervisión y control".

Actualmente existen en Uruguay dos bancos de esperma, uno de ellos con material reproductivo de donación y el otro para uso propio. Ambos son gestionados y se ubican físicamente en El Laboratori ${ }^{6}$. El Laboratorio no es una clínica de reproducción asistida ni brinda tratamientos reproductivos, sino que es una institución que nació como laboratorio de exámenes clínicos - actividad que aún sigue realizando-, pero con especialización en análisis de muestras de esperma para el diagnóstico de la infertilidad. En la década de 1990 comenzó con los bancos de esperma y actualmente desarrolla también un programa de ovodonación.

En Uruguay no existen bancos de óvulos para donación, aunque se hacen procedimientos de vitrificación de ese gameto para uso propio. Para los procedimientos con ovocitos de donación se utiliza el gameto fresco, lo que requiere la coordinación de los ciclos ovulatorios de donante y receptora, así como la coordinación de las instancias de recuperación de los ovocitos y transferencia de los embriones. Por tal motivo no se utiliza la denominación "Banco", sino "Programa de Donación de Óvulos".

Actualmente funcionan tres de estos programas. Uno que gestiona El Laboratorio y al que recurre una de las tres clínicas que realiza intervenciones de alta complejidad en el país. Las otras dos clínicas tienen sus propios Programas de Donación de Óvulos. Las tres clínicas trabajan en Montevideo, capital del país, y una de ellas trabaja también en el departamento de Salto, a 491,93 km de la capital.

Una diferencia entre los programas de donación de óvulos que llevan adelante estas clínicas es cómo proceden para la captación de donantes. El Laboratorio solo trabaja con donación pura: candidatas que se postulan para la donación de óvulos son evaluadas y si ingresan al programa y cumplen todas sus etapas reciben a cambio una

6 Este es un nombre ficticio, aunque en un ámbito pequeño como Uruguay no es difícil que se sepa a qué instituciones me estoy refiriendo. 
compensación denominada "lucro cesante" ${ }^{\prime 7}$. Uno de los restantes dos trabaja solo con donación mixta o en paralelo -que una mujer en tratamiento para concretar su deseo de filiación biológica dé parte de sus óvulos a otra mujer en tratamiento, la que a su vez la compensa costeando parte de su intervención-, y el otro tanto con donación pura como con donación mixta.

Dado que la Ley 19.167 no estipula la manera de proceder a la captación de donantes, sino que únicamente señala que la donación debe ser altruista, ambos procedimientos son legales, más allá de las disputas morales que uno y otro procedimiento generan entre quienes practican la reproducción humana asistida (Viera Cherro, 2016) ${ }^{8}$.

Desde marzo de 2015 - cuando se reglamentó la Ley 19.167- hasta el 31 de diciembre 2016 ingresaron al Fondo Nacional de Recursos (FNR) institución que gestiona el acceso a estos tratamientos mediante el sistema de copagos que establece la ley ${ }^{9}-, 1.543$ solicitudes de cobertura financiera para procedimientos de reproducción humana de alta complejidad. De estas solicitudes se autorizaron 1.306: 871 con gametos propios y 131 con ovodonación. No aparecen datos de solicitudes con espermodonación. Lo que sí sabemos es que de cada cinco muestras de esperma que se otorgan a través del Programa de Donación de Semen que gestiona El Laboratorio, cuatro están destinadas a parejas de mujeres o mujeres sin pareja (entrevista a

7 Esta compensación es de aproximadamente 400 dólares por cada procedimiento de ovodonación. En el caso del semen, se paga 60 dólares por muestra.

8 Quienes practican la donación pura señalan que en la donación en paralelo se coacciona a las pacientes para donar, mientras que quienes practican la donación en paralelo advierten que la donación pura pone en riesgo la salud de una mujer sana y que lo que se abona como lucro cesante puede concebirse como un pago por la donación.

9 Lo que el Estado aporta como copago por los tratamientos está en función de los ingresos de la mujer o pareja solicitante y disminuye según la cantidad de intentos insatisfactorios que la pareja realice.

\begin{tabular}{|l|l|l|l|}
\hline Tramo de ingreso de la pareja & $1^{\mathrm{er}}$ intento & $2^{0}$ intento & $3^{\mathrm{er}}$ intento \\
\hline $\begin{array}{l}\text { Primer tramo (hasta } 36.110 \text { pesos, } \\
\text { aproximadamente } 1200 \text { dólares) }\end{array}$ & $\begin{array}{l}\text { 0\% (lo cubre el FNR en su } \\
\text { totalidad) }\end{array}$ & $10 \%$ & $20 \%$ \\
\hline $\begin{array}{l}\text { Segundo tramo (de } 36.110 \text { a } 72.220 \\
\text { pesos) }\end{array}$ & $\begin{array}{l}25 \% \text { (la pareja debe pagar la cuarta } \\
\text { parte del costo del tratamiento) }\end{array}$ & $50 \%$ & $65 \%$ \\
\hline Tercer tramo (72.220 a 122.774 pesos) & $50 \%$ & $70 \%$ & $85 \%$ \\
\hline Cuarto tramo (122.774 a 216.660 pesos) & $75 \%$ & $85 \%$ & $90 \%$ \\
\hline Quinto tramo (más de 216.660 pesos) & $85 \%$ & $95 \%$ \\
\hline
\end{tabular}

Fuente: FNR. http://www.fnr.gub.uy/sites/default/files/tnoticia/doc/copagos_2017.pdf. Valores vigentes hasta el 31/12/2017. 
especialista, 12/03/2015). Del total de las solicitudes, 98 fueron negadas y el resto estaba a la espera de su evaluación al momento de recabar la información $(2017)^{10}$.

\section{LA ESTRATEGIA DE INVESTIGACIÓN: LABORATORIOS, CLÍNICAS, ESPECIALISTAS, RECEPTORES Y DONANTES}

La construcción de los datos que conforman el material de análisis para el presente artículo se nutrió del trabajo de campo realizado para mi tesis doctoral y supuso instancias de observación y conversaciones informales con el personal técnico en tres laboratorios, el análisis de documentación (ley, datos de donantes, hojas de procedimientos) y la realización de entrevistas a personas que intervienen, desde diversos lugares, en la gestión de material reproductivo de donación.

Desarrollé trabajo de campo en El Laboratorio, conversando informalmente con el personal que alli se desempeña y observando instancias de evaluación a quienes se candidatean a los programas de donación de gametos. Participé del procedimiento de preparación de las muestras de semen y estuve largos ratos en la sala de espera siendo partícipe muda de las dinámicas de entrada y salida del personal, pacientes y donantes. Realicé también entrevistas en profundidad al personal técnico que participa en la gestión de gametos de donación. Este trabajo fue llevado a cabo entre marzo de 2015 y noviembre de 2016. Una serie de circunstancias sobre las que aquí no voy a detenerme hizo que el personal de El Laboratorio me inhabilitara, de modo sutil y poco explícito, el acceso al campo.

Realicé asimismo observación participante en dos laboratorios en los que se hacen procedimientos in vitro ${ }^{11}$. Las clínicas en Uruguay no tienen los laboratorios para los procedimientos de alta complejidad dentro del espacio de la clínica y en algunos casos ni siquiera tienen laboratorio propio, sino que lo arriendan en momentos específicos en los cuales concentran los ciclos de alta complejidad.

El primero de los laboratorios en los cuales hice trabajo de campo está vinculado a una de las clínicas privadas que trabaja directamente con El Laboratorio en lo relativo a los procesos de adquisición de gametos para

10 Página del FNR: http://www.fnr.gub.uy/historial-de-noticias. Última consulta: $17 / 05 / 2018$.

11 Utilizaré el término laboratorios in vitro para referirme a estos. 
intervenciones in vitro. Esa observación fue hecha en una sola instancia de trabajo, durante julio de 2016. También hice observación participante en otro laboratorio en el que se realizan procedimientos de alta complejidad y que depende de otra de las clínicas privadas; eso fue en marzo de 2018.

En paralelo al trabajo de campo entrevisté en profundidad a donantes, a personas que se candidatearon para donar pero que no culminaron el proceso y a receptores de material reproductivo de donación ${ }^{12}$.

\section{CAPTACIÓN Y SELECCIÓN DE DONANTES: ENTRE LOS ATRIBUTOS DESEABLES DE LOS DONANTES Y LAS GARANTÍAS DEL COMPROMISO PARA CON LA DONACIÓN}

La gestión de gametos comienza con la captación de donantes, pero si bien la propia captación se distancia en términos formales de la selección, es en sí misma un proceso selectivo que equilibra la búsqueda de atributos deseables en los donantes al tiempo que cuida que no haya pérdidas económicas para la clínica.

12 Hice tres entrevistas a personas que se candidatearon para la donación de semen, una entrevista a un donante de semen y tres entrevistas en profundidad con candidatas para la donación de óvulos. Entrevisté también a una donante de óvulos que hacía su segunda donación, a una donante de óvulos que donó cinco veces, a una pareja que se realizó una fecundación in vitro, en el marco de la cual la mujer de la pareja donó parte de sus óvulos mediante el procedimiento de donación en paralelo, y a una pareja que fue receptora de semen de donación en dos oportunidades y que conoci durante la segunda intervención in vitro. Durante esta última entrevista resultó que la mujer de la pareja también había sido donante de óvulos en aquella primera intervención in vitro; fue una donación en paralelo. Por último, entrevisté a una receptora de óvulos de donación.

Existe una gran dificultad para acceder a personas donantes de gametos. En el caso de los donantes de semen, a todos los contacté a través de EI Laboratorio. Tres de ellos fueron entrevistados en mi lugar de trabajo y uno de ellos en mi casa. En cuanto a las candidatas a una donación de óvulos pura - es decir, que no estaban en tratamiento reproductivo-. las tres fueron contactadas a través de El Laboratorio. A dos de ellas las entrevisté en mi lugar de trabajo y a una tercera en su lugar de trabajo. Entre quienes realizaron efectivamente una donación de óvulos mediante este procedimiento, a una la contacté mediante el segundo laboratorio in vitro en el que hice trabajo de campo y la entrevisté en su lugar de trabajo y la otra se acercó a mi ámbito laboral para decirme que ella había donado; la entrevisté en su casa. A las donantes en paralelo, que contacté también a partir de la observación en el segundo laboratorio in vitro, las entrevisté con sus respectivas parejas. A una de las parejas en su cuarto de hotel, antes de regresar a su casa a $200 \mathrm{~km}$ de Montevideo y después de la transferencia del embrión, y a la otra en su casa en las afueras de Montevideo, en una zona rural. A la mujer receptora de óvulo de donación la contacté por medio de una amiga y la entrevisté en mi lugar de trabajo. Los lugares donde hice las entrevistas fueron en todos los casos elección de los entrevistados. 
El primer elemento selectivo en la captación es el direccionamiento del reclutamiento a personas entre 18 y 34 años. Para ello, en lo que hace a la donación de semen y a la donación pura de óvulos, se utilizan las redes sociales de forma segmentada y se dirige la publicidad directamente a personas dentro de estos tramos etarios. En el caso de la donación de óvulos en paralelo, el cuerpo médico informa directamente a personas en tratamiento reproductivo sobre sus posibilidades de donar óvulos, obviamente a quienes estén en condiciones de hacerlo ${ }^{13}$.

En el caso de la donación de semen, la focalización en el tramo etario de 18 a 34 años asume que garantizaría la buena calidad del material. Sin embargo, como señalan los propios especialistas, la calidad del semen ha decaído en los últimos años: "Lo que antes eran muestras de 500 millones de espermatozoides ahora es difícil de encontrar" (entrevista a especialista, 12/03/2015).

De los 98 candidatos a donante de semen que se presentaron en el período 1988-2015, 40 (casi la mitad) fueron descartados por su bajo recuento espermático, condición que aumenta a partir del año $1993^{14}$. Si consideramos que 9 candidatos desistieron de seguir en el proceso después de la primera entrevista y por tanto quedaron fuera por no llevar una primera muestra de semen a analizar, concluimos que el bajo recuento espermático fue la razón para la eliminación del $50 \%$ de quienes se candidatearon a donar este material reproductivo. Aun así, el Programa de Donación de Esperma siguió trabajando, aunque con muestras que en su gran mayoría no alcanzaban el recuento ideal al que la especialista hacía referencia. Esto nos advierte sobre lo relativa que puede ser la evaluación de la capacidad reproductiva del material biológico. El otro 50\% quedó fuera del Programa de Donación de Semen por diversos motivos, entre los que se cuentan estar fuera del rango de edad, tener calvicie precoz - un atributo no deseado-, o tener una mala actitud, lo que para el personal técnico significa estar únicamente interesado en la compensación económica por la donación.

Si la juventud ya no resulta una garantía para la calidad del material reproductivo. ¿Por qué se sigue insistiendo en buscar personas dentro de ese tramo de edad? La razón principal estriba en que no solo se

13 Están en condiciones quienes están atravesando por una intervención biotecnológica con objetivos reproductivos, pero por factores ajenos a la calidad de sus óvulos.

14 Datos del archivo de donantes de esperma de El Laboratorio analizados como parte del trabajo de campo. 
considera la calidad del material reproductivo, sino que también se evalúa la disposición de quien dona para mantenerse en el programa. Para El Laboratorio es importante poder contar con donantes que puedan efectivamente hacer el trabajo clínico ${ }^{15}$ que implica la donación (Waldby y Cooper, 2008) y que no abandonen el proceso en sus etapas iniciales. Como explicaba una de las técnicas que trabaja en el Programa de Donación de Esperma:

A nosotros no nos sirve que un candidato que fue estudiado, que está participando, deje de venir al poquito tiempo. Un candidato que fue estudiado, y que sirve como donante, a nosotros nos sirve que venga durante unos cuantos [énfasis de la entrevistada] meses (entrevista a técnica, 12/03/2015).

Es mucho lo que se invierte en el estudio de una persona candidata a donación de gametos. A quienes se candidatean se les hacen una serie de análisis que resultan en costos para quienes gestionan la donación. Se analiza el tipo de sangre para buscar compatibilidad con la mujer o con la pareja receptora y, en el caso del semen, se analiza la muestra para evaluar cantidad y calidad de los espermatozoides. También se hacen algunos exámenes genéticos para descartar que quienes donen puedan portar cromosomas para enfermedades genéticamente transmisibles. También se estudia si quienes se candidatean son portadores de marcadores genéticos de diferentes dolencias como síndrome de $X$ frágil, atrofia muscular espinal, anemia de células falciformes, alfa y beta talasemia, enfermedad de Tay-Sachs y fibrosis quística (de fibrosis quística cada vez se rastrean más mutaciones).

Portar estos cromosomas resulta en la exclusión inmediata del sistema de donación: la reproducción biotecnológica reproduce y materializa en este sentido la posibilidad de controlar los riesgos de enfermedades genéticas en la descendencia. Testear a la persona donante es parte intrínseca del procedimiento de la donación y está previsto en la Ley 19.167, lo que da cuenta de un acuerdo social tácito sobre los beneficios de la intervención biotecnológica en la reproducción, que sostiene la idea de que la reproducción de determinados genes no es deseable. La reproducción biotecnológicamente mediada con incorporación de gametos de donación (TRHA+D) materializaría este sentir común al garantizar una reproducción más perfecta que la que habilita la

15 Trabajo que supone el involucramiento de la biología de la persona y, por tanto, costos biológicos. 
reproducción no biotecnológica. Además de los estudios genéticos se hacen análisis en sangre para conocer las condiciones metabólicas y hormonales de quienes se candidatean a la donación.

El abandono por parte de una persona a la que se le han hecho esta serie de estudios genéticos supone la pérdida de una inversión económica por parte de la clínica. Por tanto, como señala otro especialista, el candidato ideal no solo cuenta con un material reproductivo acorde a las necesidades que supone la donación ${ }^{16}$, sino que es alguien comprometido con el proceso de donación, que comprende lo que esta supone y que posee las condiciones de tiempo y ausencia de compromisos familiares para mantenerse en el proceso por el tiempo suficiente para que la inversión resulte rentable:

El candidato ideal es el hombre que está en la plenitud de su fertilidad, que es la plenitud de todas sus actividades: de 19 a 25 años (...). Pero además tiene que tener posibilidades de participar, tiene que tener tiempo, no tener compromisos, no estar casado, que no venga hoy y después no pueda venir. y además tiene que entender la práctica (entrevista a especialista, 30/03/2015).

El compromiso con el proceso de la donación de la mano de la comprensión de lo que este supone son aspectos clave para el reclutamiento. Se entiende que para comprender a cabalidad lo que implica la donación resulta necesario poseer un cierto nivel de instrucción, por lo cual el modus operandi para captar donantes busca desestimular desde un comienzo a quienes no tengan cierto nivel educativo.

Una de las especialistas que trabaja en el Programa de Donación de Semen me explicó que, cuando alguien se comunica con interés en averiguar el procedimiento de donación, ella le envía una documentación con un grado importante de complejidad en cuanto a los conceptos y a la descripción de procesos y que por lo tanto requiere

16 No voy a detenerme aquí sobre las condiciones de producción de estas necesidades. Quisiera solamente remarcar que estas no derivan del material biológico, sino que son técnicamente producidas y que esta producción se rige por el exceso: exceso de espermatozoides, porque gran parte se mueren al descongelar la muestra; exceso de folículos, para poder recuperar mayor cantidad de ovocitos y para esta sobreproducción de folículos se da hormonas a donantes y receptoras; exceso de embriones in vitro, para poder contar con un margen de oportunidades en caso de que una transferencia no prospere; etc. 
algún nivel de educación (Diario de campo, El Laboratorio, 16/12/2015). Este es un modo de selección desde el proceso de captación, para tampoco invertir tiempo ni dinero en analizar candidatos que seguramente no podrán atender al compromiso que supone donar material reproductivo. Esto último explica por qué la captación se dirige a jóvenes que cursan estudios terciarios porque se supone que cuentan con el capital cultural necesario para comprender todo lo que involucra el proceso. Al mismo tiempo, en tanto el compromiso con la donación está garantizado para quienes gestionan el material reproductivo en las condiciones de formación o inteligencia de la persona donante, construir en el modo de captación estas condiciones es una forma de asegurar que estarán presentes en quien dona.

En el caso de la donación de óvulos, la ausencia de compromiso tiene efectos aun más negativos, porque no se trata solamente de no tener muestras para las intervenciones: el modo en que se procede a la donación de ovocitos supone medicar, al mismo tiempo, a donante y a receptora, por lo que quien comienza un proceso para donar óvulos y no lo culmina tira por la borda todo el esfuerzo, el tiempo y la medicación invertidos también en la receptora, como relataba trágicamente uno de los doctores que trabaja en el Programa de Donación de Óvulos que gestiona El Laboratorio sobre una donante que abandonó a último momento:

(...) una vez una paciente que empezó, estaba en el medio de la medicación y no siguió más. Al principio no la podía ubicar, fui a la casa, tenía la dirección y fui a la casa, vivía acá en la Ciudad de la Costa (...) vivía con los padres. Primero los padres no sabían. Un señor bárbaro, me dice "mi hija está en el trabajo". Al final me llamó para que pasara a buscar medicación que ella tenía. Ese tipo de cosas no pueden pasar (entrevista a especialista, 05/08/2015).

El compromiso aparece en este contexto como un elemento clave para la donación de esperma y para la de óvulos, no solo porque la ausencia de compromiso implica pérdidas monetarias para el sistema, sino porque, en un contexto social en el que resulta difícil conseguir donantes - todos los especialistas se quejan de las listas de parejas a la espera de donantes tanto de óvulos como de esperma-, la ausencia de compromiso de parte de quien dona supone directamente no contar con el material reproductivo para los procedimientos. 
El compromiso en la donación de óvulos simple es, sin embargo, diferente al de la donación en paralelo. En la donación de óvulos simple, el compromiso se evalúa a través de una serie de características que debe cumplir quien ingresa al programa de donación. Se busca que quienes ingresan tengan las mayores posibilidades prácticas para la donación: la cercanía geográfica del banco con respecto a su lugar de residencia o de actividades cotidianas, contar con tiempo para lo que implica la donación $y$, fundamentalmente, tener el apoyo de las personas cercanas, porque se entiende que no se puede mantener un proceso de donación totalmente en secreto. En este sentido, la donación de óvulos simple es homologable a la donación de esperma.

En el caso de la donación de óvulos en paralelo, el compromiso aparece como algo dado, en tanto la donante está comprometida con su propio tratamiento reproductivo. Por eso, la mañana en que hice observación en el laboratorio in vitro donde proceden a la aspiración de folículos ${ }^{17}$ de donantes puras pero también de donantes en paralelo, la médica se mostraba especialmente molesta con una paciente-donante que, según me dijo, era "difícil" (Diario de campo, 06/03/2018). La paciente no había seguido el tratamiento hormonal con la dedicación requerida. En una entrevista previa, la misma especialista me hablaba de las diferencias entre las donantes puras y las donantes mixtas:

-nos ha sucedido de pacientes que nos han abandonado en la mitad del tratamiento, que eso una paciente mixta no lo hace. (...) Es un costo agregado, porque el Fondo [se refiere al FNR] no previó que hubiera pacientes que estudiemos y que nos queden afuera, que eso significa un costo para la clínica.

-Qué interesante. ¿O sea que ustedes, desde que se aprobó la ley, en el programa de ovodonación no han tenido donantes puras?

- Sí, hemos tenido y hemos trabajado con donantes puras. Lo que pasa es que en alguna oportunidad nos surgió que la paciente abandonó el tratamiento a la mitad. Hay otras que son más constantes y que lo cumplen, y lo han hecho y tenemos embarazos. Pero no es fácil conseguir pacientes

17 El folículo es una estructura anatómico-funcional que forma parte del ovario y el ovocito es la célula que irá madurando en una parte microscópica de pared interna de un folículo a lo largo del ciclo ovárico espontáneo o estimulado. Recuperado de: https://www.institutobernabeu.com/foro/2011/11/07/los-foliculos-que-son-numerocrecimiento-y-otras-caracteristicas/. Última consulta: 01/06/2018. 
donantes puras, porque tienen que hacer un tratamiento. Tienen que aplicarse inyectables todos los dias, hacerse extracciones de sangre y ecografías los días que están indicados. A veces no vienen a la consulta, tenemos que estar llamándolas. Es más complejo el seguimiento de esas pacientes. Pero sí, no hubo más remedio $y$, bueno, buscamos pacientes donantes puras que estamos consiguiendo. Pero no con la demanda que tenemos. Estamos consiguiendo menos de las que precisamos (entrevista a especialista, 12/09/2016).

La orientación de la selección de donantes hacia personas con mediano y alto nivel de instrucción busca garantizar, en cierta medida, la posibilidad de comprender el proceso de la donación en todos sus términos y comprometerse con él. Pero estas características socioeducativas son también importantes porque se asume que se incorporan al material de donación. La biología portaría atributos actitudinales y comportamentales de las personas.

Al respecto, un ginecólogo me decía en una entrevista que realicé durante el trabajo de campo para mi tesis de maestría:

Usted ponga una de estas muchachas que tienen tres o cuatro internaciones porque estafaron, robaron... ¡Espere un poquito! Espere un poquito, nadie quiere tener esos antecedentes (entrevista a especialista, 20/07/2012).

En su estudio sobre donación de gametos en Barcelona, Bergmann (2012) señala que en ese contexto no se considera que los genes carguen con categorías sociales, sino que estas devienen de la educación y la crianza. Esta es una diferencia con el sistema estadounidense que asume que los gametos portan gustos y aptitudes de quienes los donan. A esto hay que añadir que la donación en Estados Unidos permite, además, que sean las parejas o personas destinatarias de material reproductivo de donación quienes seleccionen a los donantes del material que van a recibir.

A diferencia de lo que ocurre en Estados Unidos, tanto en Barcelona (Bergmann, 2012) como en Uruguay, la selección de donantes y la posterior asignación del material reproductivo son prerrogativas del personal técnico y no una elección de quienes transitan una intervención biotecnológica con objetivos reproductivos. Pero, a diferencia del señalamiento de Bergmann (2012) para Barcelona, hay en la forma en que se selecciona a posibles donantes en Uruguay una 
tendencia a biologizar ciertos rasgos sociales, a asumir que los genes cargan con categorías sociales ${ }^{18}$.

En el marco de estas convicciones, quienes gestionan la donación resguardarían así la reproducción de genes que cargan con categorías sociales deseables, al tiempo que inhibirian la reproducción de otros no deseables. Se trata de una decisión que impacta en vidas particulares, pero también en el conjunto de la sociedad y que, por lo tanto, articula lo individual y lo social, como lo expresa uno de los técnicos:

(...) lo primero que voy a ver es qué tipo de personas viene, porque la última pregunta que me voy a hacer es: ' $¿ A$ este lo usaría para mí?'. Ese tipo de pregunta es clave (entrevista a especialista, 30/03/2015).

La pregunta "¿Lo usaría para mí?" cobra sentido en el marco de este sistema, en el cual el personal técnico que gestiona la donación de gametos se arroga la tutela para la reproducción o inhibición de ciertas características sociales en la población. Este proceder podría interpretarse, como sugiere Ariza (2012), como un control biopolítico que ya no se ejerce sobre individuos concebidos como desviados, sino que se administra desde los procesos moleculares que les darán origen. Se tramitan así la reproducción social y la reproducción filial con criterios de deseabilidad que se controlan desde la selección de las células - gametos-que participarán en la procreación.

La exclusión del sistema de donación de quienes cargan con enfermedades genéticamente transmisibles sería la expresión socialmente aceptada de esta forma de control. La Ley 19.167 da cuenta de esta aceptación social cuando prevé controles a quienes donen gametos para evitar que porten genes vinculados a enfermedades genéticamente transmisibles. Dejar por fuera de la posibilidad de la donación a personas por otros atributos como un bajo nivel de instrucción resulta en modos más sutiles del ejercicio de este control sobre la reproducción.

18 Esta tendencia a naturalizar o biologizar ciertos rasgos sociales no es un fenómeno actual, sino que ha encontrado expresión, tanto de parte del sentido común como en el desarrollo de teorías científicas, por lo menos desde el siglo XVII (Sahlins, 1990). 


\section{REPRODUCCIÓN NATURAL: LA INSISTENCIA EN LAS SIMILITUDES FENOTÍPICAS Y LA POSIBILIDAD DEL OCULTAMIENTO}

Luego de haber explorado los atributos que se entienden como deseables para la donación de material reproductivo y cómo estos se tramitan en relación con la selección de donantes, voy a centrarme ahora en qué es lo que se privilegia para incorporar gametos de donación en el marco de una intervención biotecnológica específica, orientada a responder a los deseos de reproducción de una persona o pareja.

Este deseo, señalan Diniz y Gómez Costa (2006), es el de una descendencia biológicamente vinculada. No se trata de un deseo reproductivo a secas, sino de uno que reafirma la necesidad de una conexión biológica entre la persona o pareja que recurre a la reproducción humana asistida y el niño o niña nacida de estos procedimientos. Si no fuera así, el deseo de descendencia podría tramitarse por otras vías, como la adopción formal o informal (Luna, 2005).

Sin embargo, esta conexión biológica no es resultado directo del aporte genético de los padres sociales a la futura criatura, sino que es una construcción social que privilegia este aporte como la forma natural de vínculo filial. Desde una perspectiva constructivista de la filiación, se rompe con la idea de que existe algo a priori sobre lo cual se funda la relación social filial y se señala que los elementos que resultan culturalmente relevantes para esta relación social son parte de un proceso de construcción sociocultural.

La concepción que funda la filiación en el aporte biológico de ambos progenitores a través del coito heterosexual, constituye lo que Bestard (2009) define como el "modelo estándar" del parentesco. En este modelo la relación social que supone el emparentamiento queda asimilada a un proceso biológico que, se asume, funda de forma natural la relación social. Desde esta perspectiva, lo que se denomina "modelo estándar" del parentesco busca evidenciar que la naturalización de la biología compartida como base de la relación filial es solo una de las maneras posibles de concebir el nexo filial.

La actuación de las biotecnologías reproductivas produce justamente rupturas en los procesos biológicos que esta construcción de la filiación 
naturaliza, al incorporar gametos por fuera de la relación coital heterosexual.

Según Ariza (2013) - por lo menos en lo que refiere a Argentina que es donde ella ha realizado su investigación- existe frente a esta ruptura del orden natural un esfuerzo en las prácticas biotecnológicas tendiente a restaurar este orden. Con relación a la reconstrucción de la naturaleza del vínculo filial, este esfuerzo se orienta a buscar las similitudes fenotípicas entre donantes y parejas o mujeres receptoras.

En Uruguay también se hace énfasis en la búsqueda de similitudes fenotípicas. Se buscan similitudes en el color de ojos, en el color de pelo, en el de tez, en la altura, en el peso y en la complexión física. A estas características se suma el tipo de sangre, ya que se busca que haya compatibilidad entre donantes y receptores.

Un aspecto interesante de esta búsqueda de similitudes fenotípicas entre donantes y receptores es que se orienta gameto a gameto: se busca que el material reproductivo de donación sustituya, en términos de características fenotípicas, al gameto ausente. Esto quiere decir que, si en una pareja heterosexual se va a sustituir el óvulo, se busca una donante con un fenotipo asimilable al de la mujer de la pareja. Si se trata de ausencia de semen, se busca un donante parecido al varón de la pareja. En el caso de parejas lesbianas, se busca un donante de semen fenotípicamente similar a la mujer que no será la gestante. Estas operaciones refuerzan el modelo duogenético de reproducción, un modelo occidental reciente (Strathern, 1995) por el cual se entiende que cada gameto aporta un $50 \%$ en la descendencia.

Además de buscar emular, a través de la gestión de la donación de gametos, lo que se entiende sucedería en un proceso reproductivo no intervenido biotecnológicamente, este procedimiento permite también ocultar la injerencia biotecnológica en los procesos reproductivos y habilita lo que Bergmann (2012) define como el passing for: pasar por una familia "normal", en este caso, que no ha tenido que ser médicamente intervenida para tener descendencia.

Hay un esfuerzo en la gestión del material reproductivo heterólogo para no evidenciar su inclusión en el proyecto filial. El ejemplo más claro de ello es el etiquetado de las muestras de semen de donación: la muestra se almacena con un número y una vez que se adjudica y comienza a 
procesarse su descongelamiento y "mejoramiento" ${ }^{19}$ se la etiqueta con el apellido del destinatario - el varón de la pareja en el caso de una pareja heterosexual, la mujer inseminada en el caso de la mujer sin pareja o la pareja de lesbianas-. Se produce así un proceso de desidentificación necesario para la reidentificación de esa muestra en virtud de quién será su adjudicatario/a. Se busca de este modo, a partir de procedimientos técnicos, borrar simbólicamente la marca genética que porta el material reproductivo, marca que hasta ese entonces había sido en extremo relevante para todo el proceso que abarca desde la selección de quién dona hasta la definición de a quién se adjudica el material biológico.

El anonimato entre donantes y receptores, principio axial del sistema que antes obedecía al seguimiento de protocolos internacionales pero que ahora está sancionado por ley ${ }^{20}$, también colabora en este ocultamiento de la intromisión de material reproductivo de personas ajenas a la persona o pareja. Resulta obvio decir que el problema del ocultamiento se presenta en particular en las parejas heterosexuales, ya que en parejas homosexuales o mujeres sin pareja la necesidad de material reproductivo de personas no implicadas en el proyecto filial es totalmente imprescindible.

\section{LOS MARCADORES DE LA IDENTIDAD SOCIAL COMPARTIDA}

El énfasis en ciertas similitudes fenotípicas - como el color de tez, de ojos y de pelo- puede interpretarse no solo como una condición para el passing for (Bergmann, 2012) sino también como una muestra implícita de que las características racialmente significadas aún tienen un sentido estructurador de las relaciones sociales en la sociedad uruguaya. Solo en el marco de patrones sociales de discriminación que operan sobre características fenotípicas, la atención al color de la piel, en la gestión de gametos de donación, cobra sentido. Por otra parte, los procedimientos biotecnológicos con gametos de donación generan un escenario en el cual es posible romper con el lugar social racialmente asignado, porque

19 Este procedimiento supone la selección de aquellos espermatozoides que se consideran más aptos para la reproducción (Diario de campo, 22/06/2016)

20 Lo que agrega la ley es la obligación, para quienes gestionan la donación de material reproductivo, de llevar un registro de donantes y receptores para ser consultado a futuro. La ley prevé que una persona nacida con material genético heterólogo, así como sus descendientes, puedan conocer la identidad del donante a través de una solicitud a un magistrado competente (art. 21, cap. III). 
en teoría las parejas o personas que se asisten podrían demandar la incorporación de gametos que porten características étnico-raciales diferentes a las suyas para su procedimiento biotecnológico.

Si bien esta posibilidad teórica encuentra limitantes en la práctica debido al énfasis en la búsqueda de similitudes fenotípicas entre donantes y receptores en diálogo con la necesidad de ocultar la inclusión de material genético de donación por parte de las parejas receptoras, entendemos que el concepto de "parecido o similitud fenotípica" habilita márgenes de acción para la asignación del material reproductivo, y que en esos márgenes se procesa la producción de la similitud y la diferencia en tanto operación de producción de alteridad (Grimson, Merenson y Noel, 2012).

Esta operación cultural se dirige a marcar las distancias entre un nosotros y un otro. La construcción de la similitud o del parecido fenotípico es una manera acceder a un proceso de producción de la alteridad que se realiza en el campo de la donación de material reproductivo. Así, podemos preguntarnos qué constituye el nosotros y en qué características fenotipicas encuentra su justificación.

Me decía un especialista entrevistado que las parejas tienden a demandar ojos y piel más claros (entrevista a especialista, 30/03/2015) y que siempre hay algún pariente cercano al que atribuirle características que justifiquen un blanqueamiento de la descendencia. Esta idea de que siempre existe algún pariente con atributos étnicos deseables alimenta el mito de la sociedad europea transplantada en Uruguay (Ribeiro, 1972). Este mito se construye a partir de eventos históricos como el genocidio de los pueblos indigenas que habitaban el territorio que hoy constituye Uruguay en el proceso de conformación del Estado-nación, fundamentalmente la matanza de Salsipuedes en 1831, que diezmó el componente indígena, y de la fuerte presencia migratoria en Uruguay también en esas décadas y en las posteriores. Sin embargo, la sociedad uruguaya tiene en su composición histórica un importante aporte de la población afrodescendiente y de otros aportes poblacionales de más larga data ${ }^{21}$, además de poblaciones de origen migrante que hacen parte

21 Según datos del censo de población de 2011, los porcentajes de ascendencia de la población uruguaya son: afro o negra $4,6 \%$; asiática o amarilla $0,2 \%$, blanca $90,7 \%$ e indigena 2,4\% (Cabella, Nathan y Tenenbaum, 2013). 
del contingente de llegada más reciente proveniente de países latinoamericanos no limítrofes con Uruguay (Mides, 2017) ${ }^{22}$.

Frente a esta realidad, el mito de la sociedad uruguaya como una sociedad íntegramente conformada por inmigrantes europeos, una sociedad homogénea, blanca y excepcional en el concierto de los países latinoamericanos, europeizada, la Suiza de América, sigue funcionando:

“(...) como 'llave' explicativa para comprender la forma en que Uruguay se piensa a sí mismo como un país marcado por la excepcionalidad y despegado del resto de América Latina. La idea de una sociedad fuertemente europeizada $y$, por ello mismo, ajena a la mayoría de los problemas del continente, fue y sigue siendo una fuerte inspiración al mismo tiempo que un proyecto siempre inacabado para pensar la identidad nacional" (Uriarte y Montealegre, 2018: 95).

Señalaba un especialista que en nuestro país la búsqueda de las similitudes fenotípicas resulta fácil,

(...) porque el $95 \%$ de la población es caucásica. Es la más homogénea de toda américa. Entonces eso hace la cosa más sencilla. Un médico en Perú me decía: 'Fíjate el problema que tenemos nosotros, tenemos a los indigenas, a los negros, a los españoles, a los filipinos y a los japoneses', que los dos tienen ojos estirados, pero no son nada que ver. Entonces buscás que tenga características caucásicas y te sale un filipino. ¡Nada que ver! ¡La mezcla es terrible en esos países! Han venido de Brasil porque les han dicho: 'Si quiere donantes vaya a Uruguay o a Argentina' (entrevista a especialista, 30/03/2015).

Este mito lleva a que en la práctica se excluya del sistema de donación y recepción de material reproductivo a quienes no entren en los cánones de lo que se entiende que constituye esta homogeneidad, dando cuenta, en estos procesos de selección y adjudicación de material reproductivo de una "esencialización de la etnicidad" (Simpson, 1998: 88) y "nuevas posibilidades de racialización" (Bradby, 1996: s/p apud Simpson, 1998: 88), a través del "ascenso del ADN como el marcador definitivo de la similitud y diferencia humana" (ibídem).

22 Entre 2006 y 2011 había un 0,5\% de migrantes entre el total de residentes en el país. De 2011 a la fecha el porcentaje no cambió, pero si el lugar de procedencia del contingente migrante: aumentó la cantidad de personas provenientes de República Dominicana y de Venezuela y se mantuvo estable la migración proveniente de Perú, Chile, Colombia, Paraguay y Cuba. 
Esta racialización se imbrica asimismo con aspectos económicos que hacen a la gestión de los gametos de donación. Como explicaba otro especialista:
(...) en este momento nosotros no estamos estudiando donantes negras porque no tenemos receptoras negras. (...) Sería ridículo estudiar a una donante negra si no tengo parejas ahora que necesiten. Un día vino una mujer asiática a buscar donante, esposa de un diplomático. 'No, mire, señora, donante oriental acá no, imposible. ¿Cuántos orientales hay en Uruguay, y que sean donantes?' Porque ella quería y pretendía que fuera oriental. Si se presentara hoy una japonesa como donante no la estudio (entrevista a especialista, 05/08/2015).

Esto obliga a replantear el problema de la escasez de gametos de la que se quejan quienes trabajan en la gestión de material reproductivo de donación, así como de quienes buscan acceder a gametos de donación para sus tratamientos reproductivos. Como se puede concluir de lo dicho anteriormente, la escasez no es algo dado, sino que resulta de decisiones culturales y económicas que orientan la selección de donantes, la obtención de gametos y su asignación. Decisiones entre las que se encuentra restringir la selección de donantes de forma de reproducir lo que se entiende es la homogeneidad étnica de una comunidad y de alcanzar requisitos socialmente deseables, al tiempo que inhibir la reproducción de aquellos no deseados; realizar la asignación de gametos siguiendo modos de concepción de la filiación que naturalizan el parecido fenotípico entre ascendentes y descendientes, y prácticas económicas que buscan maximizar el beneficio.

\section{CONSIDERACIONES FINALES}

En este artículo he buscado delinear algunos de los ejes centrales de la gestión de la donación de gametos para intervenciones biotecnológicas con objetivos reproductivos en Uruguay para analizar, a partir de esta práctica, algunas de las conexiones que la sociedad uruguaya establece actualmente entre materialidad biológica, filiación, reproducción e identidad. Un aspecto a atender en dicha gestión gira en torno a cuáles son los atributos que deberian privilegiarse en la reproducción de la población, así como cuáles deberían inhibirse. En el caso de Uruguay, tales decisiones están en manos del personal técnico. 
El primer límite para la donación es portar en el ADN algún marcador vinculado a la transmisión de algunas de las enfermedades genéticas que se rastrean. En segundo lugar, portar un fenotipo que no concuerde con el que el supone hace a la generalidad de la población en el país. Cuando se buscan donantes con características fuera de esta generalidad, se los busca como una excepción circunscripta a un caso en particular. Estas directrices, y su materialización en los procedimientos técnicos, limitan el universo de posibles donantes con prerrogativas que se plantean desde el momento mismo de la captación.

La captación de donantes de gametos es en sí misma un proceso selectivo, y lo es en dos sentidos: primero, porque la captación se dirige a personas que se encuentran en un determinado tramo etario $y$ cuentan con ciertas características que son deseables para la donación, pero casi tan importante como contar con esos atributos deseables es que la persona donante demuestre su compromiso con el proceso de la donación. Sin embargo, a modo de una cinta de moebius, la posibilidad de estar comprometido con el proceso de donación implica un cierto nivel de instrucción de la persona donante. En la donación de semen y en la pura de óvulos, el nivel de instrucción como valor social que portaría el material biológico es reafirmado y a la vez depende del compromiso para con el proceso de la donación de gametos.

La gestión de la donación de gametos se muestra así como un proceso complejo que busca articular en la práctica concepciones socioculturales sobre atributos sociales deseables para la reproducción y la filiación, en diálogo con la necesidad de maximizar los costos de inversión puestos en los procedimientos.

\section{BibLiografía}

Ariza, L. (2012). Gestión poblacional del parentesco y normatividad. En D. Jones, C. Figari y S. Barrón López (Eds.). La producción de la sexualidad. Politicas y regulaciones sexuales en Argentina (pp. 127146). Buenos Aires: Biblos.

Ariza, L. (2013). The normativity of Nature: Morality, Variability and Kinship in the Gamete Exchange (Tesis doctoral inedita). Goldsmiths, University of London, Londres.

Bergmann, S. (2012). Resemblance that Matters: on Transnational Anonymized Egg Donation in Two European IVF Clinics. En M. Knecht, M. Klotz y S. Beck, S. (Eds.). Reproductive Technologies as 
Global Form. Ethnographies of Knowledge, Practices, and Transnational Encounters (pp. 331-355). Frankfurt: Campus Verlag.

Bestard, J. (2009). Los hechos de la reproducción asistida: entre el esencialismo biológico y el constructivismo social. Revista de Antropología Social, 18, 83-95.

Cabella, W., Nathan, M., y Tenenbaum, M. (2013). La población afrouruguaya en el censo 2011. En J. J. Calvo (Coord.). Atlas sociodemográfico y de la desigualdad del Uruguay, 2. Montevideo: INE-Programa de Población e Instituto de Economía de la Universidad de la República-Mides-Presidencia de la RepúblicaUNFPA. Recuperado de: http://www.ine.gub.uy/documents/10181/34017/Atlas_fasciculo_2_ Afrouruguayos.pdf/ec7ecb3f-ca0a-4071-b05f-28fdc20c94e2.

Diniz, D., y Gómez Costa, R. (2006). Infertilidad e infecundidad: acesso a nuevas tecnologías reproductivas. En C. Cáceres (Org.). Sexualidad, estigma y derechos humanos: desafíos para el acceso a la salud en América Latina (pp. 55-67). Lima: FASPA/UPCH.

Franklin, S. (1997). Embodied Progress. A Cultural Account of Assisted Conception. Nueva York: Routledge.

Grimson, A., Merenson, S., y Noel, G. (2012). Descentramientos teóricos. Introducción. En A. Grimson et al. (Comps.). Antropología Ahora (pp. 9-32). Buenos Aires: Siglo Veintiuno Editores.

Luna, N. (2005). Natureza humana criada em laboratório: biologização e genetização do parentesco nas novas tecnologias reprodutivas. História, Ciências, Saúde, 12(2), 395-417.

Ministerio de Desarrollo Social (Mides) (2017). Caracterización de las nuevas corrientes migratorias en Uruguay. Nuevos orígenes latinoamericanos. Informe final. Recuperado de: http://www.mides.gub.uy/innovaportal/file/76604/1/caracterizacion -de-las-nuevas-corrientes-migratorias-en-uruguay.pdf.

Ribeiro, D. (1972). Configuraciones histórico-culturales de los pueblos americanos. Montevideo: CEL.

Sahlins, M. (1990). Uso y abuso de la biología. Una crítica antropológica de la sociobiología. Madrid: Siglo Veintiuno Editores.

Simpson, B. (1998). Comunidades genéticas imaginadas. En M. Boivin et al. (Eds.). Constructores de otredad (pp. 88-95). Buenos Aires: Eudeba.

Strathern, M. (1995). Neccesidade de país, neccesidade de maes. Estudos Feministas, 3(2), 303-329. 
Uriarte, P., y Montealegre, N. (2018). "Al menos un puñado de gurises". Una experiencia de reasentamiento de niños sirios en Uruguay. Athenea Digital, 18(1), 91-112.

Viera Cherro, M. (2015). Tecnologías de reproducción asistida y deseo del hijo en el Río de la Plata. Montevideo: Universidad de la República.

Viera Cherro, M. (2016). Moralidades y reproducción asistida en el Río de la Plata. En C. Straw, E. Vargas, M. Viera Cherro y M. Tamanini (Orgs.). Reprodução assistida e relações de gênero na América Latina (pp. 239264). Curitiba: CRV.

Waldby, C., y Cooper, M. (2008). The Biopolitics of Reproduction. PostFordist Biotechnology and Women's Clinical Labour. Australian Feminist Studies, 23(55), 57-73. 